\title{
The fatty liver index (FLI) and incident hypertension: a longitudinal study among Chinese population
}

\author{
Kena Zhou ${ }^{1,2}$ and Jie Cen ${ }^{1,2^{*}}$
}

\begin{abstract}
Background: Hypertension and nonalcoholic fatty liver both have been considere a the sen, ús public health problems in recent years. However, the longitudinal association between hypertersion d nonalcoholic fatty liver remains unclear in Chinese population.

Methods: This study was aimed to investigate the longitudinal association to alcoholic fatty liver assessed by fatty liver index and the incident hypertension among Chinese population an, oevaluate the ability of FLI index, through comparing with the predictive value of other indexes.

Results: Four thousand six hundred eighty-six subjects (3177 males and 509 temales) were involved and followed up for 9 years. The subjects were divided into groups according to the fatty liver index. Univariate and multivariate Cox regression models were used to analyze the risk factors of / yper ion. After 9 years of follow-up, 2047 subjects developed hypertension. The overall 9-year cumulative inclu ce o HTN was $43.7 \%$, ranging from $36.0 \%$ (FLI < 30) to 75.3\% (FLI $\geq 60$ ) ( $P$ for trend $<0.001$ ). Cox regression analyses is ated that nonalcoholic fatty liver assessed by fatty liver index was independently and positively assoero d) ith the risk of incident hypertension. In receiver operating characteristic (ROC) curve analysis, the ROC curve AUU, fF/ was 0.701 (95\% Cl 0.686-0.716), which was larger than that of its components.
\end{abstract}

Conclusion: The nonalcoholic fatty liver âssessed, $\mathrm{LL}$ independently predicted the incident hypertension among the Chinese population.

Keywords: Fatty liver index, Nonalco ic fatt)/liver, Hypertension, Epidemiology

\section{Background}

Hypertension (HTN), whic is suggested to be associated with many diseases in disetes, hyperuricemia, and cardiovascular ey nts [1- has been the leading cause of death worldwie. wever, there is no accepted index that could predi- the inc nt hypertension nowadays.

Nonal ohrlic fatty hver disease (NAFLD), a spectrum of hepatic $\mathrm{P}_{\text {. }}$ logi s ranging from simple steatosis to nonalconio stea -patitis and cirrhosis, has also become a serpublic health problem in recent decades [5]. In

\footnotetext{
* Correspondence: eillen_cj@sina.com

${ }^{1}$ Ningbo No. 9 Hospital, Ningbo 315020, China

${ }^{2}$ Ningbo University, Ningbo 315020, China
}

the general Japanese population, the prevalence of NAFLD ranges from 24.6 to $29.7 \%$ [6, 7]. Moreover, it is estimated that the overall prevalence of NAFLD in mainland of China is about $20.09 \%(17.95-22.31 \%)$ [8].

Recently, the fatty liver index (FLI), as the predictor for the insulin resistance, has been associated with the fatty liver diseases [9]. Using this simple index, the fatty liver disease could be detected with considerable accuracy. In addition, NAFLD has also closely related to HTN in a cross-sectional study [10]. However, it is still unclear whether the FLI can predict the incident HTN in the Chinese population. Therefore, we performed a longitudinal population-based study in order to investigate the association between the FLI and incident HTN among Chinese population and to evaluate the ability of FLI index, through comparing with the predictive

(c) The Author(s). 2018 Open Access This article is distributed under the terms of the Creative Commons Attribution 4.0 International License (http://creativecommons.org/licenses/by/4.0/), which permits unrestricted use, distribution, and 
value of body mass index (BMI), waist circumference (WC), triglyceride (TG) and $\gamma$-glutamyltransferase (GGT).

\section{Methods}

\section{Study subjects and design}

Our population-based cohort study was conducted in the annual physical health examinations beginning from 2006 to 2015 in Zhenhai Lianhua Hospital in the city of Ningbo, China, to assess the longitudinal relationship between fatty liver index and the incident hypertension. Certain participants were excluded at study entry: (I) Individuals who had a history of HTN or overt cardiovascular diseases. (II) Individuals who were taking medicines that may affect the blood pressure. (III) Individuals who were drinking alcohol greater than $140 \mathrm{~g}$ per week for males and $70 \mathrm{~g}$ per week for females. Finally, 4686 subjects (3177 males and 1509 females) who had no HTN at baseline were evaluated for the development of HTN.

\section{Measurements}

A questionnaire for the initial health examinations in 2006 included subjects' demographic characteristics, smoking status, alcohol consumption and medical history, and the data were obtained in the health check up center of Zhenhai Lianhua Hospital under the enior physicians who were well-trained.

Standing height and body weight were mez ured wi out shoes or outer clothing for each sub ect. MI was calculated as weight in kilograms divided by ho it in meters squared. WC was measured round the smallest circumference with the measuring posjtioned between the ribs and iliac crest [11]. Sittin nod pressure was measured from the right an three times with a 1-min interval between the meayrenients after the rest for $20 \mathrm{~min}$, using an auton rted device (Omron HEM-7052; Omron 0 , Japan). The mean of three measurem nts was culated for analysis.

Venous ble od nples were obtained from the subjects in t/ morn after at least $12 \mathrm{~h}$ prior to the examin ion Blood urea nitrogen (BUN), creatinine (Cr), TG, $\mathrm{al}^{\mathrm{Cl}}$ olesterol (TC), high density lipoprotein Chol erol $\mathrm{LL}-\mathrm{C})$, low density lipoprotein (LDL-C), up acid (SUA), fasting plasma glucose (FPG), ala e aminotransferase (ALT), aspartate aminotransferase (AST), GGT, Apo-A1and Apo-B were estimated using an Olympus AU640 auto-analyzer (Olympus, Kobe, Japan). All the laboratories involved resoundingly completed the standardization.

\section{Definitions}

HTN was defined as systolic blood pressure $(\mathrm{SBP}) \geq$ $140 \mathrm{mmHg}$, diastolic blood pressure (DBP) $\geq 90 \mathrm{mmHg}$ or current drug use for HTN, in accordance with the criteria of the WHO [12]. FLI was calculated for fatty liver according to the previous studies $[9,13]: \mathrm{FLI}=\left(\mathrm{e}^{[0.953 \times \ln (\mathrm{TG})+}\right.$ $0.139 \times \mathrm{BMI}+0.718 \times \ln (\mathrm{GGT})+0.053 \times \mathrm{WC} \quad-15.745] / \quad\left(1+\mathrm{e}^{[0.953 \times}\right.$ $\ln (\mathrm{TG})+0.139 \times \mathrm{BMI}+0.718 \times \ln (\mathrm{GGT})+0.053 \times \mathrm{WC} \quad-15.745]) \times 100$, with triglycerides measured in $\mathrm{mg} / \mathrm{dl}(1, \mathrm{~g} / \mathrm{dl}=$ $0.01129 \mathrm{mmol} / \mathrm{l})$, GGT in U/l, and WC in ch Th FLI score range is $0-100$. And the subjects who had th of more of the following abnormalities w diagnosed as Metabolic syndrome (MS): (I) raised Hood ess re, systolic blood pressure (SBP) $\geq 130 \mathrm{~m}$ nHg or dia , colic blood pressure (DBP) $\geq 85 \mathrm{mmHg}$, or t tment of previously diagnosed hypertension; (II) $\mathrm{ra}_{\mathrm{a}}$ d Fru, aefined as FPG $\geq$ $6.1 \mathrm{mmol} / \mathrm{L}$, or previou v diagno d/diabetes; (III) raised triglyceride level, de nea triglycerides $\geq 1.7 \mathrm{mmol} / \mathrm{L}$; (IV) reduced HD, defin / as $\mathrm{HDL}-\mathrm{C}<1.0 \mathrm{mmol} / \mathrm{L}$; (V) WC $\geq 90 \quad n$ an Chinese men and $\geq 85 \mathrm{~cm}$ for Chinese women 17 . The estimated glomerular filtration rate (eGH was ca, ulated using the improved Chinese population $N, 0$ formula [15].

\section{Su. tical analysis}

The indamental characteristics of the samples were np/arized by descriptive statistics. Continuous variabjes were expressed as median (IQR) and categorical variables were presented as percentages (\%). Continuous variables were compared using the student's $t$ text, Mann-Whitney $U$ test, Kruskal-Wallis $H$ test or one way ANOVA depending on the normality of the data. Categorical variables between groups were compared using Chi-square text. For a statistical inference, all $p$ values are bilateral, and a $p$ value of less than 0.05 was considered statistically significant. All statistical analyses were performed using SPSS software (version 17.0, SPSS software, Chicago, IL, USA).

The study subjects were classified into three groups according to FLI at baseline: FLI $<30$ was defined as not having NAFLD, $30 \leq \mathrm{FLI}<60$ was defined as having intermediate FLI, and FLI $\geq 60$ was defined as having NAFLD. The baseline characteristics of the subjects in each group were compared. The cumulative incidence of HTN was calculated by dividing the number of cases by the numbers of subjects followed up for each FLI group. Cox proportional hazards regression models were used to analyze the risk of incident HTN for each baseline FLI.

\section{Results}

Baseline characteristics

In the study, a total of 4686 subjects ( 3177 males and 1509 females) were evaluated at baseline. The baseline demographic and clinical characteristics of the subjects are showed in Table 1. As the FLI increased, it 
Table 1 Baseline characteristics of the subjects according to FLI categories

\begin{tabular}{|c|c|c|c|c|c|}
\hline \multirow[t]{2}{*}{ Variables } & \multirow[b]{2}{*}{ All subjects $(n=4686)$} & \multicolumn{3}{|l|}{ FLI categories } & \multirow[b]{2}{*}{$P$} \\
\hline & & $<30(n=3479)$ & $30-59(n=903)$ & $\geq 60(n=304)$ & \\
\hline Gender (male/\%) & $3177 / 67.8$ & $2087 / 60.0$ & $801 / 88.7$ & 289/95.1 & $<0.001$ \\
\hline Age (years) & $40.0(34.0-50.0)$ & $39.0(33.0-50.0)$ & $44.0(36.0-53.0)$ & $41.0(34.0-51.0)$ & $<0.001$ \\
\hline $\mathrm{BMI}\left(\mathrm{kg} / \mathrm{m}^{2}\right)$ & $22.5(20.5-24.5)$ & $21.6(20.0-23.2)$ & $25.0(23.9-26.3)$ & $26.7(24.9-28.2)$ & \\
\hline $\mathrm{SBP}(\mathrm{mmHg})$ & $118.0(109.0-126.0)$ & $115.0(107.0-124.0)$ & $122.0(116.0-129.0)$ & $125.0(118.3-131.0)$ & \\
\hline $\mathrm{DBP}(\mathrm{mmHg})$ & $75.0(69.0-80.0)$ & $73.0(68.0-79.0)$ & $79.0(74.0-83.0)$ & $80.0(75.0-84.0)$ & \\
\hline WC (cm) & $78.0(71.0-84.0)$ & $74.0(69.0-79.0)$ & $86.0(83.0-90.0)$ & 91.0 & \\
\hline FLI & $12.8(4.93-30.7)$ & $7.85(3.77-16.01)$ & $41.6(34.7-50.0)$ & & 0.001 \\
\hline BUN $(\mu \mathrm{mol} / \mathrm{L})$ & $4.97(4.21-5.78)$ & $4.93(4.18-5.74)$ & $5.07(4.28-5.97)$ & .77) & 0.021 \\
\hline $\mathrm{Cr}(\mu \mathrm{mol} / \mathrm{L})$ & $72.0(61.0-81.0)$ & $70.0(59.0-80.0)$ & $78.0(72.0-85.0)$ & & $<0.001$ \\
\hline FPG (mmol/L) & $4.43(4.14-4.77)$ & $4.41(4.13-4.72)$ & $4.45(4.15-4.85)$ & & $<0.001$ \\
\hline UA $(\mu \mathrm{mol} / \mathrm{L})$ & $323.0(263.0-378.0)$ & $303.0(248.0-357.0)$ & 373.0 & $394.0,351.0-444.0)$ & $<0.001$ \\
\hline AST (U/L) & $19.0(17.0-24.0)$ & $19.0(16.0-22.0)$ & 23.0 & $-35.0)$ & $<0.001$ \\
\hline $\mathrm{ALT}(\mathrm{U} / \mathrm{L})$ & $22.0(16.0-33.0)$ & $19.0(15.0-27.0)$ & 35.0 & $48.0(33.0-74.0)$ & $<0.001$ \\
\hline$y$-GGT (U/L) & $18.0(13.0-28.0)$ & $15.0(11.0-21.0)$ & 32.0 & $60.0(37.0-97.0)$ & $<0.001$ \\
\hline TC (mmol/L) & $4.68(4.10-5.31)$ & $4.57(4.00-5.15)$ & & $5.24(4.70-5.86)$ & $<0.001$ \\
\hline TG $(\mathrm{mmol} / \mathrm{L})$ & $1.20(0.87-1.74)$ & $1.04(0.80-1.37)$ & & $2.63(1.99-3.80)$ & $<0.001$ \\
\hline $\mathrm{HDL}-\mathrm{C}(\mathrm{mmol} / \mathrm{L})$ & $1.27(1.07-1.55)$ & $1.30(1.09-1.61)$ & $.02-1.36)$ & $1.20(1.07-1.36)$ & $<0.001$ \\
\hline LDL-C (mmol/L) & $2.60(2.13-3.13)$ & $2.51(2.0$ & $2.89(2.40-3.39)$ & $3.00(246-3.55)$ & $<0.001$ \\
\hline Apo-A1 (g/L) & $1.30(1.13-1.49)$ & 1.33 & $1.21(1.06-1.37)$ & $1.20(1.07-1.35)$ & $<0.001$ \\
\hline Apo-B (g/L) & $0.90(0.75-1.07)$ & & $1.01(0.86-1.18)$ & $1.10(0.94-1.24)$ & $<0.001$ \\
\hline $\operatorname{eGFR}\left(\mathrm{mL} /\left(\min \cdot 1.73 \mathrm{~m}^{2}\right)\right)$ & $109.9(97.9-124.4)$ & & $105.5(94.3-118.4)$ & $105.5(94.8-120.5)$ & $<0.001$ \\
\hline
\end{tabular}

tended to be males and obese. In addition, $\triangle$ DBP, FPG, UA, AST, ALT, y-GGT, TC TG, LDL-y and Apo-B all tended to increase highe FLI ( $p$ $<0.001)$, whereas Apo-A1 was sig cant'y lower in subjects with higher FLI cater ies $(P<0.001)$.

\section{Relationship between Fl d inci lent HTN}

Our prospective stu wa nanducted to investigate the predictive value 1 FL $r$ incident HTN. After 9-year follow-up, 2047 (43.68\%) subjects including 1541 males and 506 females developed HTN, corresponding to $48.5 \%$ and $33.5 \%$ cumulative incidence of HTN in male and female, respectively. Also, we observed that baseline FLI predicted the incidence of HTN in a positive and dose-responsive manner (Fig. 1). The overall 9-year cumulative incidence of $\mathrm{HTN}$ was $43.7 \%$, ranging from $36.0 \%(F L I<30)$ to $75.3 \%(F L I \geq 60)$ ( $P$ for trend $<0.001$; Fig. 1). This tendency also held true for 1 - to

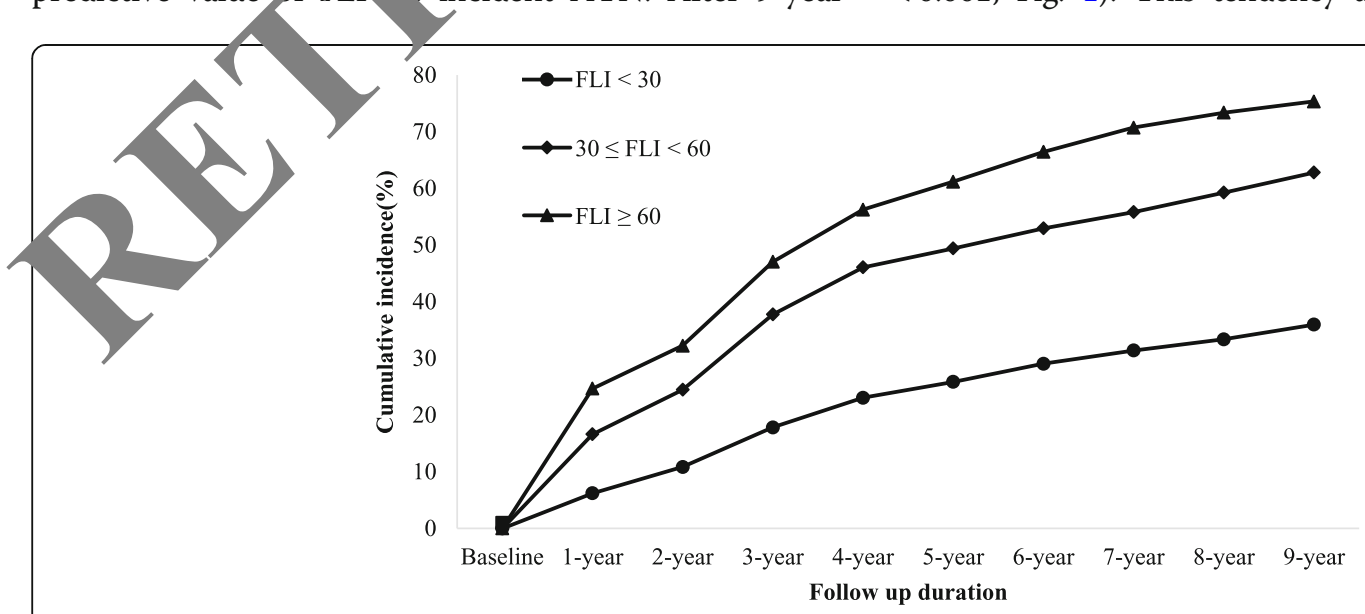

Fig. 1 The association between baseline FLI categories and the cumulative incidence of hypertension 
9-year cumulative incidences. These findings indicate that those with higher FLI groups were more likely to develop HTN. In addition, the subjects with incident HTN were predominantly male, and the baseline Age, BMI, SBP, DBP, WC, FLI, BUN, Cr, FPG, UA, AST, ALT, y-GGT, TC, TG, LDL-C, HDL-C, Apo-B and eGFR were significantly different between two groups (Table 2).

\section{The FLI and the risk of incident HTN}

In the study, we also analyzed the hazard ratio for incident HTN in each FLI group by univariate and multivariate Cox proportional hazard models (Tables 3 and 4). Compared to the lowest FLI group, the hazard ratios $(95 \% \mathrm{CI})$ for subjects in $30 \leq \mathrm{FLI}<$ 60 and FLI $\geq 60$ group were $2.17(1.97-2.40)$ and $3.00(2.61-3.46)$, respectively $(P$ for trend $<0.001)$. The same relationship between FLI and incident HTN was also revealed even after adjusting for age and gender (Mode 1), or age, gender, SBP, and DBP (Mode 2), or age, gender, and indicators of MS (Mode 3) in Table 4. These findings indicated higher FLI was associated with an increased risk of the development of HTN.

\section{ROC curve analysis}

ROC curve analyses were preformed to assess the diagnostic value of FLI and its components. The area under the ROC (AUC) curve to analyze the ability of the baseline FLI to predict the development of HTN was 0.701 (95\% CI 0.686-0.716), which was larger than that of BMI (0.684 (95\% CI 0.669-0.699), for difference $<0.01)$, WC $(0.684$ (95\% CI 0.669-0.6 , for difference $<0.01)$, TG $(0.645$ (95\% CI $0.629-0.60$ for difference $<0.01)$ and GGT $(0.633 \quad 5 \%$ CI $) .617-$ 0.649) $P$ for difference $<0.01$ ) (Fig 2 . .

\section{Discussion}

In our population-base pros tive study, it demonstrated that there w s positive, dose-response relationship between NAFL assessed by FLI and the risk of inciden $\mathrm{n} N \mathrm{~N}$ duri $/ \mathrm{g}$ a 9-year period among Chinese popu. or we found that the FLI was an independent dictor for incident HTN. Univariate and Itivariate regression analysis suggested that subjects, ih higher baseline FLI were significantly asso riated with a higher risk of incident HTN an the adjustment for confounders. Our study cont ned the findings of relevant cross-sectional

Table 2 Baseline characteristics of the subjects accorang to "ow up outcomes

\begin{tabular}{|c|c|c|c|}
\hline Variables & Subjects develop $\quad \mathrm{a}(n=204)$ & Subjects did not develop HTN $(n=2639)$ & $P$ \\
\hline Gender (male/female, n) & $1541 / 506$ & $1636 / 1003$ & $<0.001$ \\
\hline Age (years) & $44.0(36.0 \quad 54.0)$ & $38.0(33.0-46.0)$ & $<0.001$ \\
\hline BMI $\left(\mathrm{kg} / \mathrm{m}^{2}\right)$ & $23.6(21.8$ & 21.7(19.8-23.6) & $<0.001$ \\
\hline SBP $(\mathrm{mmHg})$ & res & 112.0(105.0-120.0) & $<0.001$ \\
\hline $\mathrm{DBP}(\mathrm{mmHg})$ & & $71.0(67.0-76.0)$ & $<0.001$ \\
\hline WC $(\mathrm{cm})$ & 7.0) & $75.0(69.0-81.0)$ & $<0.001$ \\
\hline FLI & & 8.03(3.63-19.96) & $<0.001$ \\
\hline BUN $(\mu \mathrm{mol} / \mathrm{L})$ & $09(4.29-5.96)$ & $4.86(4.15-5.66)$ & $<0.001$ \\
\hline $\mathrm{Cr}(\mu \mathrm{mol} / \mathrm{L})$ & $74.0(64.0-83.0)$ & $71.0(60.0-80.0)$ & $<0.001$ \\
\hline & $4.53(4.21-4.89)$ & 4.37(4.09-4.66) & $<0.001$ \\
\hline & $342.0(284.0-395.0)$ & $306.0(250.0-364.0)$ & $<0.001$ \\
\hline & $20.0(17.0-25.0)$ & 19.0(16.0-23.0) & $<0.001$ \\
\hline & $25.0(17.0-37.0)$ & $20.0(15.0-30.0)$ & $<0.001$ \\
\hline 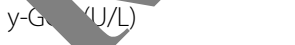 & $21.0(15.0-34.0)$ & $16.0(11.0-24.0)$ & $<0.001$ \\
\hline TC (mp,ol/L) & $4.83(4.28-5.50)$ & $4.56(3.99-5.14)$ & $<0.001$ \\
\hline TG $(\mathrm{mmol} / \mathrm{L})$ & $1.38(1.01-2.02)$ & $1.07(0.80-1.51)$ & $<0.001$ \\
\hline $\mathrm{HDL}-\mathrm{C}(\mathrm{mmol} / \mathrm{L})$ & $1.26(1.07-1.52)$ & $1.27(1.08-1.58)$ & 0.020 \\
\hline LDL-C (mmol/L) & $2.73(2.24-3.29)$ & $2.51(2.04-3.03)$ & $<0.001$ \\
\hline Apo-A1 (g/L) & $1.29(1.13-1.50)$ & $1.30(1.13-1.48)$ & 0.815 \\
\hline Apo-B (g/L) & $0.97(0.81-1.14)$ & $0.85(0.71-1.01)$ & $<0.001$ \\
\hline $\operatorname{eGFR}\left(\mathrm{mL} /\left(\min \cdot 1.73 \mathrm{~m}^{2}\right)\right)$ & 108.0(95.0-122.0) & 111.6(100.2-126.2) & $<0.001$ \\
\hline
\end{tabular}




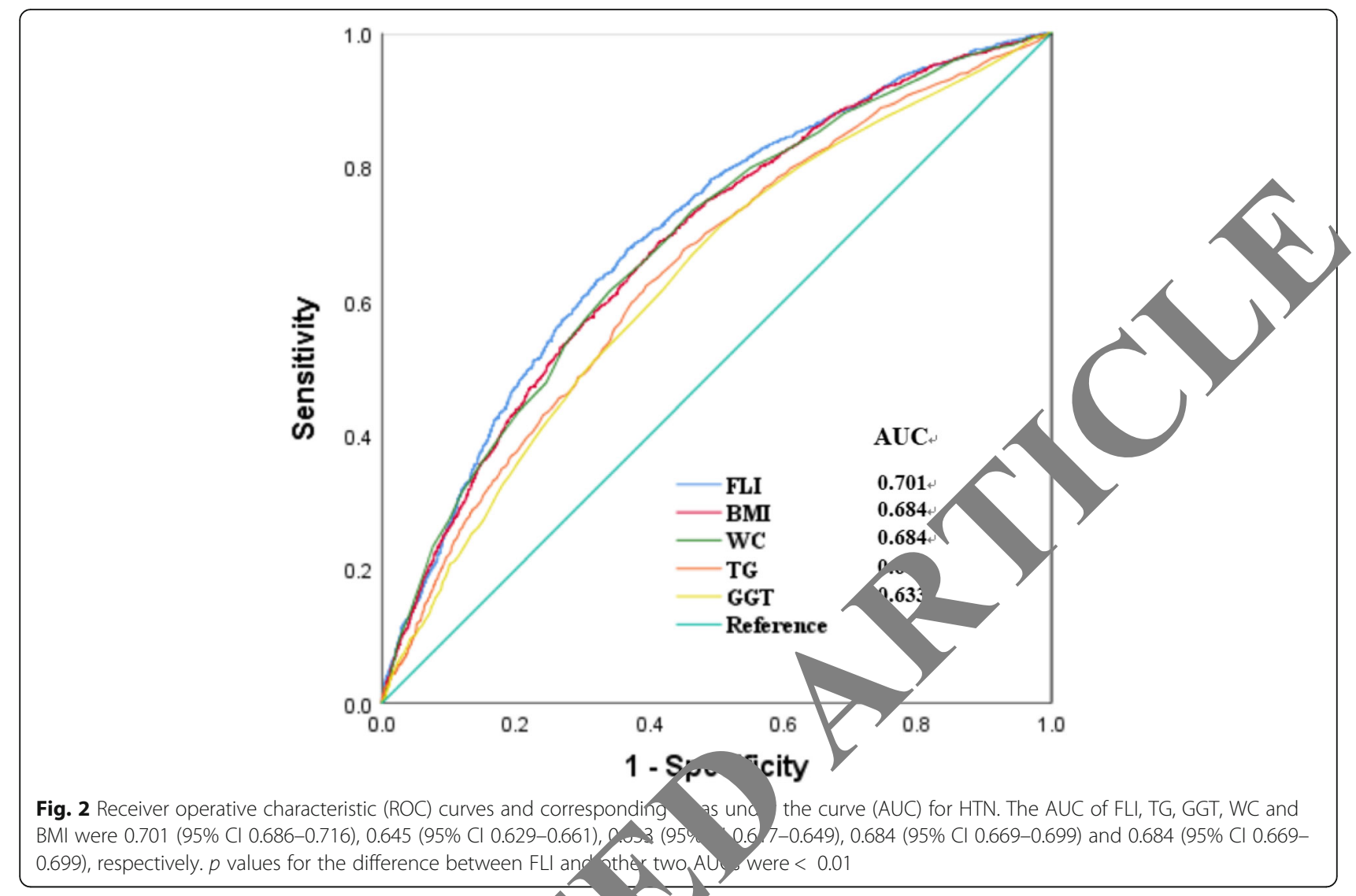

studies, which observed an indepen aent positiv, relationship between NAFLD and inci nt HTN $[10,16]$, and importantly provides evidence ousality for the relationship. The results show that the FLI index may be an effective pridry for the incident HTN, through compar with the components of the FLI.

Currently, increasing tudies [17-19] suggest that lipids and $G G$ vel may se an independent predictor of incident ATN. Owever, in our ROC analysis, the AUC of the FLI inc, $x$ in diagnosing HTN was larger than th. BM WC, TG and GGT. These indicated thathe $P_{L}$ ind $x$ was more effective for predicting the - cide it HT, $\sqrt{ }$, compared with the components of the t. nace.

Th cllowing hypotheses about the mechanism by which NAFLD participates in the development of HTN may be possible. The first and foremost is the insulin resistance (IR). To the best of our knowledge, several studies have demonstrated that NAFLD is associated with insulin resistance [20,21], which may increase the sympathetic nervous system activity, induce the strong vasoconstriction effect, make the vascular smooth muscle proliferation, increase the synthesis and release of endothelin, and finally lead to the elevation of blood pressure [22, 23]. The other explanation is related to the renin-angiotensin system. Wu Y, et al. [24] demonstrated that NAFLD has been associated with renin-angiotensin system in a recent study. And of course it was also the cause of incident HTN.

In addition, previous epidemiological studies have shown that the FLI was the well-known predictor for the development of nonalcoholic fatty liver and diabetes $[25,26]$. Our results indicated that the FLI predicted the subsequent occurrence of HTN in a positive and dose-dependent manner. Therefore, the early detection of the FLI may be beneficial for early interventions to prevent HTN later in life among Chinese population.

The 9-year longitudinal population-based study and a large number of subjects were our major strengths. Also, the longitudinal study expanded the observation to establish the temporal sequence between NAFLD assessed by FLI and the later risk of HTN in Chinese population. Moreover, the selection bias was less likely to appear in the present study as annual health check-ups in state-owned companies are mandatory in 
Table 3 Univariate Cox Proportional Hazard models of development of HTN during 9-year follow-up

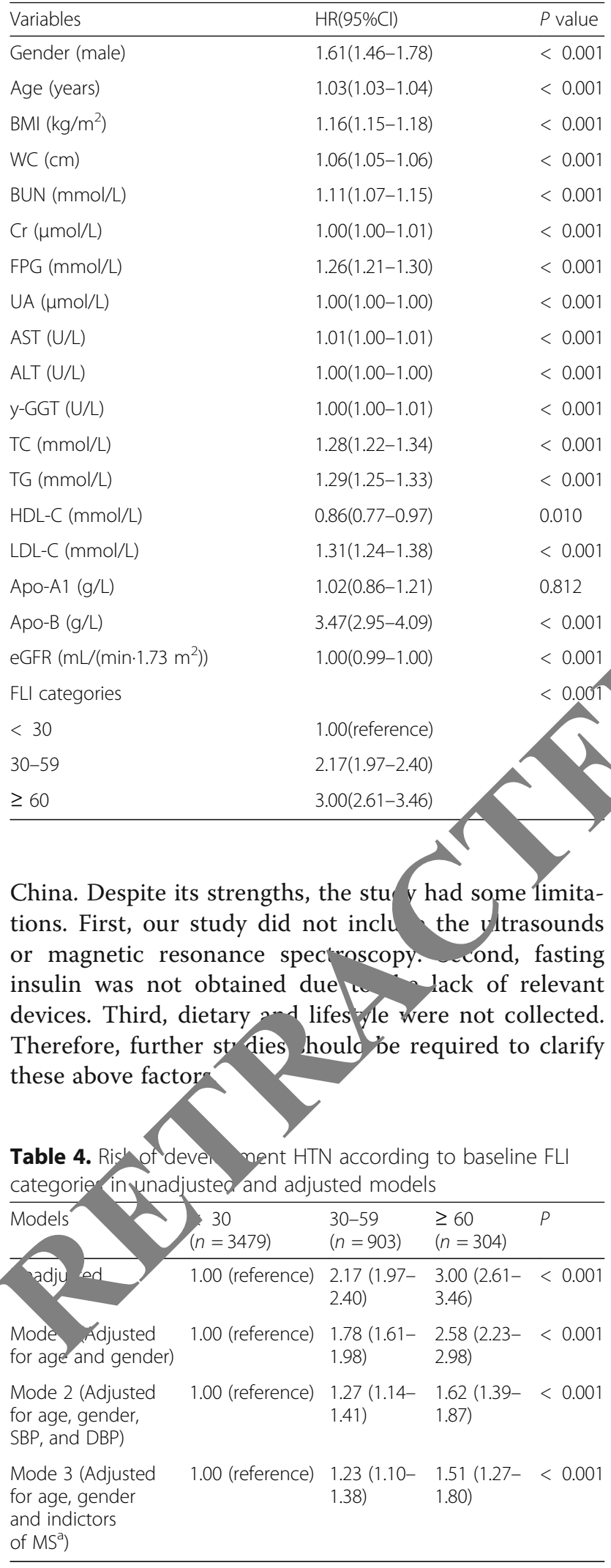

Including WC, SBP, DBP, FPG, HDL-C, TG

\section{Conclusion}

In conclusion, the results of the study showed that nonalcoholic fatty liver assessed by FLI independently predicted the incident HTN, and suggested that the FLI should be closely monitored and it may be beneficial for HTN prevention.

\section{Abbreviations}

ALT: Alanine aminotransferase; AST: Aspartate aminotransferase; BM mass index; BUN: Blood urea nitrogen; Cr: Creatinine; CV\%: Cardiovasc disease; DBP: Diastolic blood pressure; eGFR: Estimatea merular P'tran rate; FLI: Fatty Liver Index; FPG: Fasting plasma glud se; $A_{4}$. High density lipoprotein cholesterol; HTN: Hypertension; IR: ' isulin resistan, ZDL-C: Low density lipoprotein; NAFLD: Nonalcoholic fatty iver disease: SBP: Systolic blood pressure; SUA: Serum uric acid; TC Toto nolesterol TG: Triglyceride; WC: Waist circumference; $\gamma-G G T: \gamma-G$

\section{Acknowledgements}

We appreciate all participant wh ok part id our study.

Ethics approval and corm to part/_ipant

The study was perf ed i accordance with the guidelines of the Declaration of Helsink. stum, protocol and the form of consent were approved by the Ethics mittee of the Institutional Review Board of Zhenhai Lian Hospital a ld Ningbo No. 9 Hospital. Written informed consent was clbtar $\mathrm{jm}$ all participants before our gathering of data and the study.

\section{Ava ility of data and materials}

All dat re fully available without restriction.

A. ors' contributions

KNZ carried out the study design, analysis and interpretation of data, and drafted the manuscript. JC participated in the study and the acquisition of data. JC conceived the study, participating in its design and coordination, and helped in drafting the manuscript. Both authors read and approved the final manuscript.

\section{Consent for publication}

Not applicable.

\section{Competing interests}

The authors declare that they have no competing interest.

\section{Publisher's Note}

Springer Nature remains neutral with regard to jurisdictional claims in published maps and institutional affiliations.

Received: 22 July 2018 Accepted: 28 August 2018

Published online: 11 September 2018

\section{References}

1. Cryer MJ, Horani T, DiPette DJ. Diabetes and hypertension: a comparative review of current guidelines. J Clin Hypertens (Greenwich). 2016;18(2):95-100.

2. Mancia G, Grassi G, Borghi C. Hyperuricemia, urate deposition and the association with hypertension. Curr Med Res Opin. 2015;31(Suppl 2):15-9.

3. Liu X, Sun N, Yu T, et al. The independent and joint Association of Blood Pressure, serum Total homocysteine, and fasting serum glucose levels with brachial-ankle pulse wave velocity in Chinese hypertensive adults. Int Heart J. 2016;57(5):627-33.

4. Zanchetti A. Cardiovascular consequences of hypertension: therapeutic effects on organ damage and on cardiovascular events. Blood Press Suppl. 1994;1:1-4.

5. Weiß J, Rau M, Geier A. Non-alcoholic fatty liver disease: epidemiology, clinical course, investigation, and treatment. Dtsch Arztebl Int. 2014; 111(26):447-52. 
6. Nishioji K, Sumida Y, Kamaguchi M, Mochizuki N, Kobayashi M, Nishimura T, et al. Prevalence of and risk factors for non-alcoholic fatty liver disease in a nonobese Japanese population, 2011-2012. J Gastroenterol. 2015;50:95-108.

7. Equchi $\mathrm{Y}$, Hyogo H, Ono M, Mizuta T, Ono N, Fujimoto $\mathrm{K}$, et al. Prevalence and associated metabolic factors of nonalcoholic fatty liver disease in the general population from 2009 to 2010 in Japan: a multicenter large retrospective study. J Gastroenterol. 2012;47:586-95.

8. Li Z, Xue J, Chen P. Prevalence of nonalcoholic fatty liver disease in mainland of China: a meta-analysis of published studies. J Gastroenterol Hepatol. 2014;29(1):42-51.

9. Bedogni G, Bellentani S, Miglioli L, et al. The fatty liver index: a simple and accurate predictor of hepatic steatosis in the general population. BMC Gastroenterol. 2006;6:33.

10. López-Suárez A, Guerrero JM, Elvira-González J, et al. Nonalcoholic fatty liver disease is associated with blood pressure in hypertensive and nonhypertensive individuals from the general population with normal levels of alanine aminotransferase. Eur J Gastroenterol Hepatol. 2011;23(11):1011-7.

11. Zhou M, Ma X, Li H, et al. Serum osteocalcin concentrations in relation to glucose and lipid metabolism in Chinese individuals. Eur J Endocrinol. 2009; 161(5):723-9.

12. Guidelines Subcommittee. 1999 World Health Organization - international society of hypertension guidelines for the management of hypertension. $J$ Hypertens. 1999;17:151-83.

13. Zelber-Sagi S, Webb M, Assy N, et al. Comparison of fatty liver index with noninvasive methods for steatosis detection and quantification. World J Gastroenterol. 2013;19(1):57-64

14. Joint Commission on Revisions of Chinese Guideline for the Management of Dyslipidemia in Adults, 2016 (in Chinese) Chinese guideline for the management of dyslipidemia in adults. Chin J Cardiol 2016,44(10):833-853.

15. Xun $L$, Cheng W, Hua T, et al. Assessing glomerular filtration rate (GFR) in elderly Chinese patients with chronic kidney disease (CKD): a comparison of various predictive equations. Arch Gerontol Geriatr. 2010;51(1):13-20.

16. Aneni EC, Oni ET, Martin SS, et al. Blood pressure is associated with the presence and severity of nonalcoholic fatty liver disease across the spectrum of cardiometabolic risk. J Hypertens. 2015;33(6):1207-14.

17. Sánchez-lñigo L, Navarro-González D, Pastrana-Delgado J, et al. Assc of triglycerides and new lipid markers with the incidence of bypextens a Spanish cohort. J Hypertens. 2016;34(7):1257-65.

18. Kunutsor SK, Apekey TA, Cheung BM. Gamma-glutamylt anste and risk of hypertension: a systematic review and dose-respon meta-an is of prospective evidence. J Hypertens. 2015;33(12):23 3-81.

19. Kim NH, Huh JK, Kim BJ, et al. Serum gamma-gl amyl transferase level is an independent predictor of incident hypertensior Korean ad ults. Clin Exp Hypertens. 2012;34(6):402-9.

20. Gaggini M, Morelli M, Buzzigoli E, et al. alcoholic tatty liver disease (NAFLD) and its connection with insulin ress dyslipidemia, atherosclerosis and coronary hoart diseas Nutrients. 2013;5(5):1544-60.

21. Asrih M, Jornayvaz FR. Metabolle drome ad nonalcoholic fatty liver disease: is insulin resistap . lin Mal Col Endocrinol. 2015;418(Pt 1):55-65.

22. Tack CJ, Smits P, Will nsen al. Lructs of insulin on vascular tone and sympathetic nery is system in DM. Diabetes. 1996;45(1):15-22.

23. Zemel MB. Ins in tance vs. byperinsulinemia in hypertension: insulin regulation of $\mathrm{Ca} 2+$ tra ort and $\mathrm{ca}(2+)$-regulation of insulin sensitivity. J Nutr. 190 s; $12 S(6$ Suppl):: of-43S.

24. Wu Y $\mathrm{K}$ Zhang $Y$, el al. Lipid disorder and intrahepatic reninangiot system ctivation synergistically contribute to non-alcoholic liver se Liver Int. 2016;36(10):1525-34

Av ig X, Xu, , Chen $Y$, et al. Validation of the fatty liver index for lic fatty liver disease in middle-aged and elderly Chinese. vicine (Baltimore). 2015;94(40):e1682.

26. $\mathrm{D}$, Choi $E$, Ahn SV. Fatty liver index as a simple predictor of in ident diabetes from the KoGES-ARIRANG study. Medicine (Baltimore). 2016;95(31):e4447.

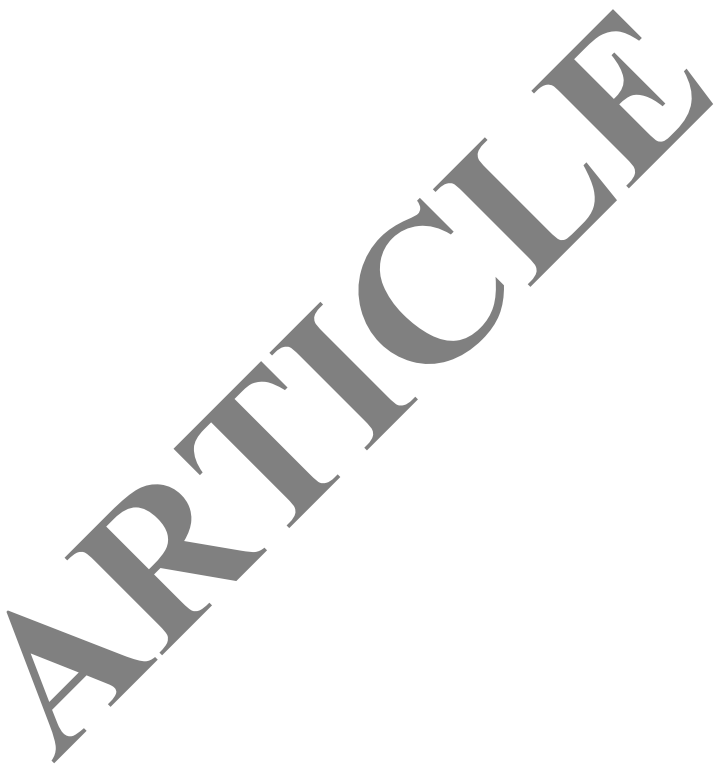

Ready to submit your research? Choose BMC and benefit from:

- fast, convenient online submission

- thorough peer review by experienced researchers in your field

- rapid publication on acceptance

- support for research data, including large and complex data types

- gold Open Access which fosters wider collaboration and increased citations

- maximum visibility for your research: over $100 \mathrm{M}$ website views per year

At $\mathrm{BMC}$, research is always in progress.

Learn more biomedcentral.com/submissions 